\title{
Diarrheal knowledge and preventative behaviors among the caregivers of children under 5 years of age on the Tonle Sap Lake, Cambodia
}

This article was published in the following Dove Press journal: Research and Reports in Tropical Medicine

\author{
Hasan S Merali' \\ Mieko S Morgan ${ }^{2,3}$ \\ Chaweewon Boonshuyar ${ }^{3}$ \\ 'Department of Pediatrics, McMaster \\ Children's Hospital, McMaster \\ University, Hamilton, ON, Canada; \\ ${ }^{2}$ Services for Health in Asian and \\ African Regions (SHARE), Phnom \\ Penh, Cambodia; ${ }^{3}$ Faculty of Public \\ Health, Thamasart University, Bangkok, \\ Thailand
}

Correspondence: Hasan S Merali Division of Pediatric Emergency Medicine, McMaster Children's Hospital, I280 Main Street West, HSC-2N49I, Hamilton, ON L8S 4KI, Canada

$\mathrm{Tel}+19055212100$

Email Hasan_Merali@post.harvard.edu
Purpose: Although Cambodia has made significant progress toward lowering the under-five mortality rate since 2000 , diarrhea still accounts for $6 \%$ of the total number of these deaths. A vast majority of these deaths is preventable. In this study, we sought to examine diarrheal knowledge and preventative behaviors of caregivers of children under the age of 5 years, to determine caregiver factors associated with knowledge and behavior scores.

Patients and methods: This was a cross-sectional household-level study conducted in two floating villages on the Tonle Sap Lake, Cambodia between January and February 2014. Caregivers of children under 5 years of age in the villages of Steung Trov and Moat Khla were asked 31 true or false questions to assess their knowledge of diarrhea. They also filled out a questionnaire to assess diarrhea preventative behaviors (DPBs). Comparison of mean scores to categorical caregiver variables was performed using one-way ANOVA analysis. Spearman's rank correlation was applied to identify the relationship between the knowledge and preventative behavior scores and independent quantitative variables.

Results: A total of 101 caregivers of 161 children under 5 years of age were interviewed. The majority of them $(85.1 \%)$ was classified as having good knowledge and scored $>80 \%$ on the assessment. Those with Khmer ethnicity (mean=28.10) scored significantly higher than those with Vietnamese ethnicity (mean 26.00; $p=0.004$ ). Older age was correlated with higher knowledge scores $(\rho=0.2260 ; p=0.023)$ and DPB scores $(\rho=0.2320 ; p=0.019)$. Significant differences were found between the DPB score and ethnicity, educational background, and wealth $(p<0.01)$. Conclusion: Although the majority of caregivers had high diarrheal knowledge scores, preventative behaviors for diarrhea as assessed by this study were poor among almost all study participants. Vietnamese, wealthier, older, and more educated participants had better prevention scores. Future interventions in this remote region may benefit from these data as a guide to determine which specific preventative behaviors should be targeted.

Keywords: diarrhea, Cambodia, children

\section{Introduction}

Despite significant worldwide progress in reducing child deaths over the last decades, diarrhea remains a leading cause of mortality in children under 5 years of age. Globally, diarrhea accounts for $11 \%$ of all under 5 years deaths, translating into 760,000 childhood deaths annually. ${ }^{1}$ The vast majority of these deaths is preventable through improvements in water, sanitation, hygiene, nutrition, breastfeeding, and immunization. $^{2}$ It is important to note that $>90 \%$ of cases of acute diarrhea can be treated effectively with oral rehydration. ${ }^{3}$ Other effective treatments include zinc, intravenous fluids, and antibiotics in select cases. ${ }^{3}$ 
Since 1990 with the introduction of the Millennium Development Goals (MDGs), Cambodia has achieved significant success in reducing childhood mortality. By 2015, Cambodia had exceeded the MDG of reducing the under-five mortality below 39 deaths per 1,000 live births and had lowered it to 29 deaths per 1,000 live births. ${ }^{4}$ This is significant considering the under-five mortality in 1990 which was 117 per 1,000 live births. ${ }^{4}$ Specifically for diarrhea, Cambodia has also made significant improvements since 1990. The comprehensive Global Burden of Disease Study in 2010 demonstrated that in 1990, diarrheal disease was the second overall cause of years of life lost (YLL), whereas in 2010, it was ranked eighth. This represented 626,000 YLLs in 1990 and 117,00 YLLs in 2010 , or an $82 \%$ difference. ${ }^{5}$ Diarrhea, however, remains a leading cause of death in children under 5 years of age, in Cambodia, accounting for $6 \%$ of deaths in this age group. ${ }^{4}$ Yet only $35 \%$ of children under 5 years of age diagnosed with diarrheal disease are receiving oral rehydration salts. ${ }^{4}$

Improper treatment of childhood diarrhea has been shown to be due to misperceptions and lack of knowledge in both caregivers and healthworkers. ${ }^{6,7}$ Addressing these gaps in knowledge and behavior is critical to ensure that diarrhea is prevented and children are treated appropriately. ${ }^{8}$ This is particularly important in remote regions where caregivers have limited access to health care and health education. One such region is the Tonle Sap Lake, Cambodia where many inhabitants live in remote floating villages and have access only to intermittent health care. ${ }^{9}$ The purpose of this study was to assess caregivers' diarrheal knowledge and DPB in two of the villages. This is the first ever household-level study conducted in these villages.

\section{Patients and methods}

This was a cross-sectional household-level study conducted in two floating villages on the Tonle Sap Lake, Cambodia between January and February 2014. The villages are Moat Khla and Steung Chrov, both situated in the Chikreng District of Siem Reap Province. These villages are outside the reach of the Cambodian Ministry of Health and are among the poorest in the country. The villages were chosen as study sites because they are served by a local nongovernmental organization, The Lake Clinic, which provides primary health care to communities on the Tonle Sap Lake, allowing access to the villages. ${ }^{9}$ This study was completed in partnership with The Lake Clinic given their experience and expertise in this remote region.
In each village, the chief was first asked about all households with children under 5 years of age. Using this information, as well as data provided by study respondents, each household that was known to have children under 5 years of age was approached. The inclusion criteria for the caregivers were that they had to be the primary provider for at least one child under the age of 5, they consented to participate with written informed consent and they were of legal age to participate in the study. For those caregivers that were illiterate, verbal consent was obtained. Caregivers who had only children over the age of 5 years, or were unavailable, were excluded.

A personal interview with the participating caregiver was then conducted by a researcher and a research assistant. All interviews were conducted in Khmer or Vietnamese. For those caregivers that spoke Vietnamese, a village health volunteer fluent in both Khmer and Vietnamese acted as an interpreter. The interview consisted of questions on general characteristics, 31 true or false questions to assess knowledge of diarrhea, and an assessment of diarrhea preventative behaviors (DPB) using a questionnaire. Receipt of measles vaccine has been shown to decrease diarrhea; hence, this was included in the general characteristics of the children. ${ }^{10}$ Both the knowledge assessment and the DPB questionnaire were developed using literature review. The knowledge assessment included questions on the definition, cause, transmission, danger signs, and prevention of diarrhea. It was pilot tested first with 10 caregivers to assess language and sequencing of the questions. It was then pretested on an additional 39 caregivers to assess the reliability of the instrument. The Cronbach's alpha coefficient was 0.777 , demonstrating a high level of internal consistency. The caregivers who participated in the pretest were not included in the final study. The DPB questionnaire consisted of four subset elements: sanitation, hygiene, safe drinking water, and food preparation and feeding. The overall score was out of 65 .

This study received a certificate of ethical approval from the Ethical Review Committee for Human Research, Faculty of Public Health, Mahidol University, Bangkok, Thailand. In Cambodia, The Lake Clinic has a signed memorandum of understanding with the Cambodian Ministry of Health specifically to provide a venue for cooperative and complimentary activities with academic bodies.

\section{Statistical analysis}

Data entry was done using Epidata 3.1, and then the data were exported to SPSS version 18.0 for statistical analysis. 
Participants were classified as having poor knowledge $(<60 \%$ correct), fair knowledge ( $60 \%-80 \%$ correct), or good knowledge ( $>80 \%$ correct) based on their overall score and score within each subsection. Participants were initially classified the same way for the DPB score, but since none of the participants scored $>80 \%$, they were reclassified as poor $(>50 \%)$, very poor $(25 \%-50 \%)$, and extremely poor $(<25 \%)$.

In the descriptive analysis, number, percent, mean, and standard deviation were used to describe the variables. The participants' scores for both knowledge and DPB were compared to categorical independent variables using one-way analysis of variance (ANOVA). The relationship between the quantitative independent variables (age, number of children under 5 years of age in the household, and number of years living in the household) were compared to both the knowledge score and DPB score using Spearman's rank correlation. This method was also used to describe the relationship between the knowledge score (both overall and prevention knowledge) and DPB score. The knowledge scores were also compared to each of the subsections of the DPB score. The significance level for all analyses was set at $5 \%$.

\section{Results}

\section{General characteristics}

In total, 101 caregivers were interviewed in both the villages, and these caregivers were responsible for 161 children under 5 years of age. The majority of caregivers were female (95\%), married (92.1\%), ethnically Khmer (80.2\%), and the mother of the child $(88.1 \%)$. The mean age for the caregivers was 31.6 years (SD 9.9 years) and the majority $(53.5 \%)$ had either no formal education or only primary school. The average length that a caregiver was living in a particular village was 15.69 years (SD 9.99 years) as shown in Table 1 .

In total, there were 161 children in our sample, cared for by the 101 caregivers. The mean age of the children was 23.05 months (SD 16 months). There was nearly an equal split between male $(50.3 \%)$ and female $(49.7 \%)$. A majority of the children $(54.1 \%)$ were vaccinated against measles. Most of the children $(54.4 \%)$ had experienced diarrhea in the last month. Of the children who had diarrhea in the month prior to the survey, the vast majority $(97.5 \%)$ had watery diarrhea and a large portion $(45.7 \%)$ had blood and mucous in the diarrhea (Table 2).

\section{Diarrheal knowledge}

The average overall score for the diarrheal knowledge questionnaire was 27.68 (SD 2.98) out of a total of 31 possible
Table I General characteristics of 101 caregivers of children under 5 years of age

\begin{tabular}{|c|c|c|}
\hline General characteristics & Number & Percentage \\
\hline \multicolumn{3}{|l|}{ Sex } \\
\hline Male & 5 & 5.0 \\
\hline Female & 96 & 95.0 \\
\hline \multicolumn{3}{|l|}{ Age in years } \\
\hline $17-29$ & 52 & 51.6 \\
\hline $30-39$ & 33 & 32.8 \\
\hline $40-70$ & 16 & 16.0 \\
\hline \multicolumn{3}{|l|}{ Marital status } \\
\hline Single & 1 & 1.0 \\
\hline Married & 93 & 92.1 \\
\hline Divorced & I & 1.0 \\
\hline Separated & 2 & 2.0 \\
\hline Widowed & 4 & 4.0 \\
\hline \multicolumn{3}{|l|}{ Ethnicity } \\
\hline Khmer & 81 & 80.2 \\
\hline Vietnamese & 20 & 19.8 \\
\hline \multicolumn{3}{|l|}{ Relationship to child } \\
\hline Mother & 89 & 88.1 \\
\hline Father & 5 & 5.0 \\
\hline Grandparent & 5 & 2.0 \\
\hline Aunt & 2 & 2.0 \\
\hline \multicolumn{3}{|c|}{ Highest level of education completed } \\
\hline None & 54 & 53.5 \\
\hline Primary or lower secondary & 47 & 46.5 \\
\hline \multicolumn{3}{|l|}{ Length of stay in village (years) ${ }^{a}$} \\
\hline$<1$ & 4 & 4.0 \\
\hline $1-9$ & 22 & 22.2 \\
\hline $10-19$ & 36 & 36.4 \\
\hline$\geq 20$ & 37 & 37.4 \\
\hline
\end{tabular}

Note: ${ }^{299}$ valid households.

Table 2 General characteristics of $16 \mid$ children under 5 years of age

\begin{tabular}{lll}
\hline General characteristics & Number & Percentage \\
\hline Sex & 81 & \\
Male & 80 & 40.3 \\
Female & & 49.7 \\
Age in months ${ }^{\mathrm{a}}$ & 21 & 13.1 \\
$0-5$ & 23 & 14.4 \\
$6-1 \mathrm{I}$ & 34 & 21.3 \\
I2-23 & 29 & 18.1 \\
$24-35$ & 53 & 33.1 \\
$36-48$ & 0 & 0 \\
$49-59$ & & \\
Measles vaccination & & \\
Yes & 86 & 54.1 \\
No & 73 & 45.9 \\
Diarrhea within last month & & \\
No & & 45.6 \\
Yes & 68 & 54.4 \\
$\quad$ Watery stool & 81 & 97.5 \\
Bloody stool with mucous & 79 & 45.7 \\
\hline
\end{tabular}

Notes: a 160 valid cases. ${ }^{b} 159$ valid cases. ${ }^{c} \mid 49$ valid cases. 
points. Overall, most caregivers $(85.1 \%)$ scored higher than $80 \%$ on the test and were classified as having good knowledge. Thirteen caregivers (12.9\%) were classified as having fair knowledge, and only two caregivers $(2.0 \%)$ were classified as having poor knowledge. Caregivers demonstrated strong knowledge in answering questions about the cause, transmission, and prevention of diarrhea with $89.1 \%, 88.1 \%$, and $94.1 \%$, respectively, answering $>80 \%$ of questions correctly. They had lower scores when answering questions regarding the definition of diarrhea and danger signs in children with diarrhea. Only 38 (37.1\%) caregivers were classified as having good knowledge of the definition of diarrhea and $72(71.3 \%)$ had good knowledge of the danger signs in children with diarrhea (Table 3 ).

Using one-way ANOVA, the knowledge scores were compared with categorical variables of caregivers' general characteristics. The only significant variable in the analysis was ethnicity, with caregivers of Khmer ethnicity having higher knowledge scores (mean=28.10; SEM=0.29) than those of Vietnamese ethnicity (mean=26.00; SEM=0.87;

Table 3 Caregiver knowledge of diarrhea on 31 item true/false questionnaire

\begin{tabular}{llll}
\hline $\begin{array}{l}\text { Level of } \\
\text { knowledge }\end{array}$ & $\begin{array}{l}\text { Poor } \\
\text { N (\%) }\end{array}$ & $\begin{array}{l}\text { Fair } \\
\text { N (\%) }\end{array}$ & $\begin{array}{l}\text { Good } \\
\text { N (\%) }\end{array}$ \\
\hline Overall & $2(2.0)$ & $13(12.9)$ & $86(85.1)$ \\
$\quad$ Definition & $23(22.8)$ & $40(39.6)$ & $38(37.6)$ \\
Cause & $5(5.0)$ & $6(5.9)$ & $90(89.1)$ \\
Transmission & $6(5.9)$ & $6(5.9)$ & $89(88.1)$ \\
Danger signs & $5(5.0)$ & $24(23.8)$ & $72(71.3)$ \\
Prevention & $4(4.0)$ & $2(2.0)$ & $95(94.1)$ \\
\hline
\end{tabular}

$p=0.004$ ) (Table 4). The independent variables of age, length of stay in the village, and number of children under 5 years of age in the household were analyzed using Spearman's rank correlation against knowledge scores. In this analysis, only age was correlated with older caregivers having more knowledge $(\rho=0.2260 ; p=0.023)$.

\section{Diarrhea preventative behaviors}

Caregivers scored between 7 (10.8\%) and 39 (60.0\%). The average score was 22.36 (SD 6.07) out of a possible 65 points. Given the scoring was so low among caregivers, they were classified as poor $(>50 \%-60 \%)$, very poor $(25 \%-50 \%)$, or extremely poor $(<25 \%)$ for the DPB score. Overall, only five caregivers $(5.0 \%)$ were classified as poor, $68(67.3 \%)$ as very poor, and $28(27.7 \%)$ as extremely poor. Within the subsections, the majority of subjects was classified as poor $(74.3 \%)$ only for food preparation and feeding practice. For both sanitation practice and safe drinking water practice, the majority were classified as extremely poor, $73.3 \%$ and $80.2 \%$, respectively (Table 5).

Using one-way ANOVA, significant differences were found between the DPB score and ethnicity $(p<0.001)$, educational background $(p=0.001)$, and wealth $(p<0.001)$. Vietnamese caregivers, those who had some formal education and those who were wealthier were found to have higher DPB scores (Table 6). The independent variables of age, length of stay in the village, and number of children under the age of 5 in the household were analyzed using Spearman's rank correlation against DPB scores. Only age was correlated with older caregivers having a higher DPB score $(\rho=0.2320 ; p=0.019)$.

Table 4 One-way analysis of variance of mean diarrheal knowledge score by characteristics of caregiver

\begin{tabular}{|c|c|c|c|c|}
\hline \multirow[t]{2}{*}{ Characteristics of caregiver } & \multirow[t]{2}{*}{ Total responses } & \multicolumn{2}{|c|}{ Overall knowledge score } & \multirow[t]{2}{*}{$p$-value } \\
\hline & & Mean & SEM & \\
\hline \multicolumn{5}{|l|}{ Sex } \\
\hline Male & 5 & 26.60 & 2.20 & \\
\hline Female & 96 & 27.74 & 0.29 & 0.408 \\
\hline \multicolumn{5}{|l|}{ Ethnicity } \\
\hline Khmer & 81 & 28.10 & 0.29 & \\
\hline Vietnamese & 20 & 26.00 & 0.87 & $0.004^{*}$ \\
\hline \multicolumn{5}{|l|}{ Educational background } \\
\hline No formal education & 54 & 27.74 & 0.37 & \\
\hline Primary school or above & 47 & 27.62 & 0.48 & 0.837 \\
\hline \multicolumn{5}{|c|}{ Children experiencing diarrhea within last month } \\
\hline Yes & 66 & 27.95 & 0.32 & \\
\hline No & 35 & 27.17 & 0.61 & 0.211 \\
\hline \multicolumn{5}{|l|}{ Household assets and wealth } \\
\hline Poverty score $<15$ & 51 & 27.35 & 0.46 & \\
\hline Poverty score $\geq 15$ & 50 & 28.02 & 0.38 & 0.264 \\
\hline
\end{tabular}

Note: $*_{p}$-value $<0.05$. 
No significant correlation was found between the overall knowledge score and the overall DPB score, or any of the subsection DPB scores. Significant correlation was found between the prevention knowledge score and the overall DPB score $(\rho=0.3170 ; p=0.001)$, sanitation practice DPB subsection $(\rho=0.1970 ; p=0.048)$, and safe drinking water practice DPB subsection $(\rho=0.2020 ; p=0.043)$ (Table 7).

\section{Discussion}

To our knowledge, this is the first household-level study of villagers living in remote floating villages on the Tonle Sap Lake, Cambodia. Since these villagers live in such a rural region with limited access to health care, it is critical that

Table 5 Diarrhea preventative behavior score in 101 caregivers

\begin{tabular}{llll}
\hline $\begin{array}{l}\text { Diarrhea preventative } \\
\text { behaviors }\end{array}$ & $\begin{array}{l}\text { Extremely } \\
\text { poor, } \\
\text { N (\%) }\end{array}$ & $\begin{array}{l}\text { Very poor, } \\
\text { N (\%) }\end{array}$ & $\begin{array}{l}\text { Poor, } \\
\text { N (\%) }\end{array}$ \\
\hline Overall & $28(27.7)$ & $68(67.3)$ & $5(5.0)$ \\
$\quad$ Sanitation practice & $74(73.3)$ & $0(0)$ & $27(26.7)$ \\
Hygiene practice & $16(15.8)$ & $73(72.3)$ & $12(11.9)$ \\
Food preparation and & I (I.0) & $25(24.8)$ & $75(74.3)$ \\
$\quad$ feeding practice & & & \\
Safe drinking water practice & $81(80.2)$ & $20(19.8)$ & $0(0)$ \\
\hline
\end{tabular}

we assess knowledge and behavior of hygiene and prevention practices so that intervention programs may be better targeted.

The caregivers in this study had good overall knowledge of diarrhea, including prevention knowledge with the vast majority $(85.1 \%)$ scoring $>80 \%$. Further analysis demonstrated a difference between Khmer and Vietnamese caregivers, with Khmer providers having higher overall mean scores. There are several possible reasons for this. First, observationally, the healthcare providers who work in these remote fishing villages note that Vietnamese families tend to avoid seeking health care because they are undocumented immigrants and fear repercussion. This is not uncommon and is known to be true even in high-income countries. For example, parental legal status of Latino children in the USA has been shown to be a barrier to access mental health services for children. ${ }^{11}$ This type of behavior may contribute to having less knowledge because they are less likely to attend the educational sessions on health and hygiene run by The Lake Clinic. Another possible explanation is that there are traditional practices and beliefs unique to these Vietnamese immigrants. Studies in both Vietnam ${ }^{12}$ and elsewhere ${ }^{13}$ have demonstrated that traditional home

Table 6 One-way analysis of variance of mean diarrhea preventative behavior (DPB) score by characteristics of caregiver

\begin{tabular}{|c|c|c|c|c|}
\hline \multirow[t]{2}{*}{ Characteristics of caregiver } & \multirow{2}{*}{$\begin{array}{l}\text { Total } \\
\text { responses }\end{array}$} & \multicolumn{2}{|c|}{ DPB score } & \multirow[t]{2}{*}{$p$-value } \\
\hline & & Mean & SEM & \\
\hline \multicolumn{5}{|l|}{ Sex } \\
\hline Male & 5 & 26.60 & 2.36 & \\
\hline Female & 96 & 22.14 & 0.62 & 0.110 \\
\hline \multicolumn{5}{|l|}{ Ethnicity } \\
\hline Khmer & 81 & 21.30 & 0.63 & \\
\hline Vietnamese & 20 & 26.65 & 1.32 & $<0.001 *$ \\
\hline \multicolumn{5}{|l|}{ Educational background } \\
\hline No formal education & 54 & 20.56 & 0.75 & \\
\hline Primary school or above & 47 & 24.43 & 0.89 & $0.00 I^{*}$ \\
\hline \multicolumn{5}{|c|}{ Children experiencing diarrhea within last month } \\
\hline Yes & 66 & 21.70 & 0.69 & \\
\hline No & 35 & 23.60 & 1.14 & 0.135 \\
\hline \multicolumn{5}{|l|}{ Household assets and wealth } \\
\hline Poverty score $<15$ & 51 & 19.84 & 0.66 & \\
\hline Poverty score $\geq 15$ & 50 & 24.92 & 0.88 & $<0.001 *$ \\
\hline
\end{tabular}

Note: ${ }^{*} p$-value $<0.05$.

Table 7 Spearman's rank correlation between diarrheal knowledge and diarrhea preventative behaviors (DPB) of I0I caregivers

\begin{tabular}{llllll}
\hline & $\begin{array}{l}\text { Overall diarrhea } \\
\text { preventative behaviors }\end{array}$ & $\begin{array}{l}\text { Sanitation } \\
\text { practice }\end{array}$ & $\begin{array}{l}\text { Hygiene } \\
\text { practice }\end{array}$ & $\begin{array}{l}\text { Food and feeding } \\
\text { practices }\end{array}$ & $\begin{array}{l}\text { Safe drinking water } \\
\text { practice }\end{array}$ \\
\hline Overall knowledge & 0.0350 & -0.1390 & 0.0380 & 0.0200 & 0.1140 \\
& $(0.731)$ & $(0.167)$ & $(0.703)$ & $(0.840)$ & $(0.257)$ \\
Prevention knowledge & 0.3170 & 0.1970 & 0.1960 & 0.1710 & 0.2020 \\
& $(0.001)^{*}$ & $(0.048)^{*}$ & $(0.050)$ & $(0.088)$ & $(0.043)^{*}$ \\
\hline
\end{tabular}

Notes: $p$-value in italics and parentheses; ${ }^{*} p$-value $<0.05$ 
treatments are used frequently for diarrhea. The correlation we observed in our study of older caregivers having higher knowledge scores is consistent with the literature. In rural Uganda, Isingoma et al demonstrated that younger mothers lack nutritional knowledge for young children. ${ }^{14}$ Similarly, in Iran, caregiver knowledge of diarrhea in children under 5 years of age has been shown to have significantly increased in older caregivers. ${ }^{15}$

For the DPB score, participants scored much lower, with only five caregivers scoring $>50 \%$. Interestingly, a significant difference was again found in ethnicity, but for the DPB score, Vietnamese caregivers scored higher than Khmer caregivers. This could also be due to differences in traditional practices for treatment and prevention of diarrhea, which also has been shown to occur in Cambodia. ${ }^{16}$ The finding of higher scores associated with greater wealth and education is consistent with other studies. Higher wealth levels have been shown to be associated with improved handwashing practices ${ }^{17}$ and lower incidence of diarrhea. ${ }^{18}$ Caregivers with higher education also have lower incidence of diarrhea. ${ }^{18}$ Similar to the knowledge score, older caregivers also scored better on the DPB score, consistent with the previous literature on caregiver practices. ${ }^{19}$

Although no correlation was found between the overall knowledge score and the DPB score and subsections, significant correlations were found between prevention knowledge and the overall DPB score, sanitation practice DPB subsection, and the safe drinking water practice DPB subsection. This highlights the need for targeted interventions at improving diarrhea preventative knowledge. In order to improve knowledge and prevention behaviors for caregivers, several methodologies have been employed, including direct teaching, ${ }^{20,21}$ video teaching, ${ }^{22}$ and radio messaging. ${ }^{20}$ In Ceará, Brazil, Joventino et al performed a randomized trial using an educational video to promote maternal self-efficacy in preventing childhood diarrhea. ${ }^{22}$ The data collectors were blinded to group allocation, and the authors found that the average scores for the intervention group were higher. ${ }^{22}$ In Zambia, a multifaceted approach of direct teaching, community events, and radio messaging demonstrated increased self-reporting of exclusive breastfeeding in infants aged 0-5 months, but no difference in handwashing with soap (observation), oral rehydration salt solution preparation (demonstration), and zinc use in diarrhea treatment (selfreport). ${ }^{20} \mathrm{~A}$ recent community-based cluster randomized trial demonstrated a $35 \%$ reduction in the incidence of underfive diarrheal disease where caregivers were given direct messaging as well as soap. ${ }^{21}$ This is similar to the reduction of diarrhea episodes with handwashing promotion found in a large Cochrane review evaluating both high-income and low-income countries. ${ }^{23}$

As a result of this study, The Lake Clinic began a comprehensive program to address hygiene and nutrition among the villagers on the Tonle Sap Lake in 2015. These interventions continue to be implemented by The Lake Clinic's community outreach team of two midwives. This team regularly visits families to discuss health needs and facilitates educational sessions on both hygiene and nutrition in the floating schools. Additionally, the outreach team has created "Mothers Clubs" in which groups of mothers can discuss hygiene and nutrition issues and learn from each other. In 2016, The Lake Clinic was successful in obtaining an International Community Access to Child Health grant from the American Academy of Pediatrics to promote and assist in the creation of floating gardens. This project aims to further improve the nutritional status of all of the villagers served by The Lake Clinic.

There are several limitations to this study. First, there is selection bias in the way the participants were selected. In this study, the chief of each village and neighbors, were asked about households where children aged under 5 years live. Although this should capture the majority of caregivers, it is certainly possible that some were missed using this selection method. There were also caregivers who were identified but not interviewed because they were not available or did not consent. Second, there may be recall bias when caregivers were giving responses. The responses were not corroborated with medical records or other sources. Finally, there may be response bias. When caregivers were asked about specific DPBs, it is possible that they answered in a way that they thought they should respond, based on previous education they had received, not how they actually behave.

The results of this study could be further utilized by The Lake Clinic and other nongovernmental organizations working in this remote region to target hygiene and sanitation interventions. It is important to focus interventions on those who have lower wealth, are younger, and less educated. Any program that is implemented should focus on diarrhea prevention and based on evidence from previous trials should also include giving caregivers soap..$^{21,23}$

\section{Conclusion}

This is the first household-level study in the remote floating villages of the Tonle Sap Lake, Cambodia. We found that most caregivers of children under 5 years of age have good knowledge of diarrhea, but poor knowledge of DPBs. 
Caregivers who were Vietnamese, older, wealthier, and more educated had higher DPB scores. Diarrhea prevention knowledge was positively correlated with higher DPB scores overall and in two subsections. This study highlights the importance of teaching diarrhea prevention and identifies several target populations for intervention in these remote communities.

\section{Acknowledgments}

The authors would like to thank all of the staff who work with The Lake Clinic, Cambodia. Without their support, this project would not have been possible. The authors would also like to thank Kristiina Skogberg for her assistance in editing the manuscript.

\section{Disclosure}

Preliminary results from this study were previously presented at the American Academy of Pediatrics National Conference and Exhibition in 2015. ${ }^{24}$ The authors report no conflicts of interest in this work.

\section{References}

1. World Health Organization. Ending Preventable Deaths from Pneumonia and Diarrhoea by 2025. The Integrated Global Action Plan for Pneumonia and Diarrhoea (GAPPD). UNICEF: World Health Organization; 2013. Available from: http://www.who.int/maternal_child_adolescent/ news_events/news/2013/gappd_launch/en/. Accessed May 1, 2017.

2. World Health Organization. Diarrhoea: Why Children Are Still Dying and What Can Be Done. UNICEF: World Health Organization; 2009. Available from: http://www.who.int/maternal_child_adolescent/documents/9789241598415/en/. Accessed May 1, 2017

3. World Health Organization. The Treatment of Diarrhoea. A Manual for Physicians and Other Senior Health Workers. Geneva: World Health Organization; 2005. Available from: http://www.who.int/maternal_ child_adolescent/documents/9241593180/en/. Accessed May 1, 2017

4. Cambodia Health Data - 2015 Profile. Countdown to 2030; 2015. Available from: http://countdown2030.org/country-profiles/cambodia. Accessed May 1, 2017.

5. Global Burden of Disease Profile: Cambodia. Institute for Health Metrics and Evaluation; 2010. Available from: http://www.healthdata. org/sites/default/files/files/country_profiles/GBD/ihme_gbd_country_report_cambodia.pdf. Accessed January 2, 2018.

6. Digre P, Simpson E, Cali S, Lartey B, Moodley M, Diop N. Caregiver perceptions and utilization of oral rehydration solution and other treatments for diarrhea among young children in Burkina Faso. J Glob Health. 2016;6(2):020407.

7. Zwisler G, Simpson E, Moodley M. Treatment of diarrhea in young children: results from surveys on the perception and use of oral rehydration solutions, antibiotics, and other therapies in India and Kenya. J Glob Health. 2013;3(1):010403.
8. Unger CC, Salam SS, Sarker MS, Black R, Cravioto A, El Arifeen S. Treating diarrhoeal disease in children under five: the global picture. Arch Dis Child. 2014;99(3):273-278.

9. Merali HS, Morgan JF, Uk S, Phlan S, Wang LT, Korng S. The Lake Clinic - providing primary care to isolated floating villages on the Tonle Sap Lake, Cambodia. Rural Remote Health. 2014;14:2612.

10. Bawankule R, Singh A, Kumar K, Shetye S. Does measles vaccination reduce the risk of acute respiratory infection (ARI) and diarrhea in children: a multi-country study? PLoS One. 2017;12(1):e0169713.

11. Finno-Velasquez M, Cardoso JB, Dettlaff AJ, Hurlburt MS. Effects of parent immigration status on mental health service use among latino children referred to child welfare. Psychiatr Serv. 2016;67(2):192-198.

12. Kaljee $L$, Thiem VD, von Seidlein $L$, et al. Healthcare use for diarrhoea and dysentery in actual and hypothetical cases, Nha Trang, Viet Nam. J Health Popul Nutr. 2004;22(2):139-149.

13. Carter E, Bryce J, Perin J, Newby H. Harmful practices in the management of childhood diarrhea in low- and middle-income countries: a systematic review. BMC Public Health. 2015;15:788.

14. Isingoma BE, Samuel M, Edward K, Maina GW. Socioeconomic and demographic factors influencing feeding practices, morbidity status, and dietary intakes of children aged 7-24 months in rural Uganda. Ecol Food Nutr. 2017;56(1):1-16.

15. Ghasemi AA, Talebian A, Alavi NM, Mousavi GA. Knoweldege of mothers in management of diarrhea in under-five children, in Kashan, Iran. Nurs Midwifery Stud. 2013;1(3):158-162.

16. Chassagne F, Hul S, Deharo E, Bourdy G. Natural remedies used by Bunong people in Mondulkiri province (Northeast Cambodia) with special reference to the treatment of 11 most common ailments. J Ethnopharmacol. 2016;191:41-70.

17. Aluko OO, Afolabi OT, Olaoye EA, Adebayo AD, Oyetola SO, Abegunde OO. The management of the faeces passed by under five children: an exploratory, cross-sectional research in an urban community in Southwest Nigeria. BMC Public Health. 2017;17(1):178.

18. Budhathoki SS, Bhattachan M, Yadav AK, Upadhyaya P, Pokharel PK. Eco-social and behavioural determinants of diarrhoea in under-five children of Nepal: a framework analysis of the existing literature. Trop Med Health. 2016;44:7.

19. Azage M, Haile D. Factors associated with safe child feces disposal practices in Ethiopia: evidence from demographic and health survey. Arch Public Health. 2015;73:40.

20. Greenland K, Chipungu J, Curtis V, et al. Multiple behaviour change intervention for diarrhoea control in Lusaka, Zambia: a cluster randomised trial. Lancet Glob Health. 2016;4(12):e966-e977.

21. Hashi A, Kumie A, Gasana J. Hand washing with soap and WASH educational intervention reduces under-five childhood diarrhoea incidence in Jigjiga District, Eastern Ethiopia: a community-based cluster randomized controlled trial. Prev Med Rep. 2017;6:361-368.

22. Joventino ES, Ximenes LB, da Penha JC, Cordeiro de Oliveira Andrade L, de Almeida PC. The use of educational video to promote maternal self-efficacy in preventing early childhood diarrhoea. Int J Nurs Pract. Epub 2017 Jan 25.

23. Ejemot-Nwadiaro RI, Ehiri JE, Arikpo D, Meremikwu MM, Critchley JA. Hand washing promotion for preventing diarrhoea [review]. Cochrane Database Syst Rev. 2015;9:CD004265.

24. Merali HS, Morgan M, Boonshuyar C. Diarrhea preventative behaviours among the caregivers of children under five years of age on the Tonle Sap Lake, Cambodia. Poster presented at: American Academy of Pediatrics National Conference and Exhibition; October 25; 2015; Washington, DC. 
Research and Reports in Tropical Medicine is an international, peerreviewed, open access journal publishing original research, case reports, editorials, reviews and commentaries on all areas of tropical medicine, including: Diseases and medicine in tropical regions; Entomology; Epidemiology; Health economics issues; Infectious disease; Laboratory science and new technology in tropical medicine; Parasitology; Public health medicine/health care policy in tropical regions; and Microbiology. The manuscript management system is completely online and includes a very quick and fair peer-review system. Visit http://www.dovepress. com/testimonials.php to read real quotes from published authors.

Submit your manuscript here: https://www.dovepress.com/research-and-reports-in-tropical-medicine-journal 